\title{
EL PROCESO DE LA INQUISICIÓN CONTRA LA LECTURA DEL ARTE DE RAMON LLULL EN LA UNIVERSIDAD DE ZARAGOZA
} (1610)

\author{
POR \\ RAFAEL RAMIS BARCELÓ \\ Universitat de les Illes Balears
}

\section{RESUMEN}

Este escrito pretende explicar el proceso de la Inquisición de Zaragoza contra la lectura del Arte de Ramon Llull en la Universidad en 1610. El maestro Agustín Núñez Delgadillo enseñó el Arte de Llull, pero el Rector y el Claustro le prohibieron hacerlo, aunque pocos años antes Felipe II había apoyado públicamente el lulismo en diferentes lugares, especialmente en Alcalá. Para entender mejor el proceso, habrá que enmarcarlo en las difíciles relaciones entre el Rey, el Papa y las diferentes corrientes e intereses de la Iglesia y de los Reinos Hispánicos.

PALABRAS CLAVE

Lulismo; Zaragoza; Agustín Núñez Delgadillo; Inquisición; Universidad.

THE PROCESS OF THE INQUISITION AGAINST THE TEACHING OF THE ART OF RAMON LLULL AT THE UNIVERSITY OF ZARAGOZA

\section{ABSTRACT}

This article tries to explain the process of the Tribunal of the Inquisition of Zaragoza against the explanation of the Art of Ramon Llull at the University in 1610. Master Agustín Núñez Delgadillo taught the Art of Ramon Llull but the Chancellor and the Senate forbade doing it. 
However, Philip II had protected Lullism and encouraged its explanation in several places, especially in Alcalá. In order to better understand the process, it is explained by contextualization of the historical references and by the clarification of the difficult relationship among the King of Spain, the Pope and the different ideological trends and interests of the Roman Catholic Church and the interests of the different Spanish Kingdoms.

\section{KEY WORDS}

Lullism; Zaragoza; Agustín Núñez Delgadillo; Spanish Inquisition; University.

$\begin{array}{ll}\text { Recibido/Received } & \text { 03-04-2013 } \\ \text { Aceptado/Accepted } & \text { 22-02-2014 }\end{array}$

Uno de los grandes temas que ocupó a la Inquisición española, a caballo entre el siglo XVI y el XVII, fue el lulismo. Felipe II y su hijo Felipe III estuvieron directamente implicados en los asuntos lulianos, en un período complejo, lleno de tensiones y de malestar tanto para la Iglesia como para la Monarquía Hispánica. En algunos trabajos anteriores ${ }^{1}$ se han expuesto las vicisitudes del lulismo en esa época, corriente ideológica sobre la que todavía quedan cuestiones de importancia por investigar, algunas de las cuales yacen en diferentes fondos a la espera de un estudio detallado.

En este artículo se presenta una documentación inédita referente al proceso que hizo la Inquisición de Zaragoza contra el Maestro Agustín Núñez Delgadillo, que había enseñado el Arte de Ramon Llull en sede universitaria. Dicha documentación sirve para mostrar las contradicciones de la Inquisición frente al lulismo y representa un punto de inflexión en la historia del lulismo hispánico. Desde el reinado de los Reyes Católicos hasta Felipe II, el lulismo fue una doctrina protegida por los monarcas y promovida en buena parte de las universidades. La Inquisición tuvo

${ }^{1}$ Siguen siendo imprescindibles: Pérez Martínez, L. 1961. Intervención de la Santa Sede en la Causa Luliana Roma: Universidad Gregoriana [Tesis doctoral inédita]; Pérez Martínez, L. 1962. "La causa luliana en Roma durante el reinado de Felipe II". Anthologica Annua 10: 193-249; Pinto Crespo, V. 1982. "La censura inquisitorial, inquietud e incertidumbre: el caso de Ramon Llull (1559-1610)", Miscelánea de la Universidad Autónoma de Madrid: 293-314. Cantoblanco: Universidad Autónoma de Madrid. 
siempre sospechas contra el lulismo y durante el reinado de Felipe II hubo momentos de gran tensión. Una vez muerto el monarca, la Inquisición se sintió más libre para castigar el lulismo, pese a la protección que teóricamente brindaba Felipe III a la doctrina de Llull.

Esta prohibición del lulismo en la Universidad de Zaragoza es la última de las grandes prohibiciones del lulismo académico en España. Como indicaron los hermanos Carreras Artau, el lulismo hispano en el XVII se replegó hacia las cátedras mallorquinas y a la Orden Franciscana. ${ }^{2}$ Empezó, casi paralelamente a la prohibición en Zaragoza, el proceso diocesano de beatificación de Ramon Llull, lo que dio lugar a situaciones nuevamente paradójicas. Antes de entrar en ello, conviene resumir brevemente el marco ideológico, político y religioso del lulismo.

\section{EL LULISMO Y LA INQUISICIÓN ${ }^{3}$}

Durante la segunda mitad del siglo XIV los monarcas de la Corona de Aragón (Pedro IV, Juan I y Martín I) habían dado varios privilegios para favorecer la explicación de la doctrina luliana. El inquisidor Nicolau Eimeric fue su detractor más enconado e hizo lo posible para presentar ante el Papa los errores de Llull. Tras muchas denuncias ante la corte pontificia, el papa Gregorio XI mandó al Arzobispo de Tarragona la carta Nuper dilecto filio, fechada el 5 de junio de 1372, en la que le ordenaba que recogiera y examinara las obras de Ramon Llull que trataran de la fe y que quemara las que contuvieran errores contra la misma.

Nicolau Eimeric clamaba contra el tono apocalíptico de los lulistas del momento, que mezclaban las doctrinas de Llull con las de Arnau de Vilanova. Según el propio inquisidor, los lulistas decían que las doctrinas lulianas eran superiores a las demás, que provenían de una inspiración del Espíritu Santo y que se podían aprender con facilidad para combatir los errores de los herejes. ${ }^{4}$

Eimeric había señalado en su Directorium Inquisitorum de 1375 cien artículos antilulianos, que eran la síntesis de quinientas opiniones

${ }^{2}$ Carreras Artau, J. y T. 1941. Historia de la filosofía española: 271. Madrid: Real Academia de Ciencias Físicas.

${ }^{3}$ Véase Pérez Martínez, L. 1989. "Lulismo e Inquisición a principios del siglo XVII". En Escudero, J. A. (ed.): Perfiles jurídicos de la Inquisición española: 732-735. Madrid: Universidad Complutense de Madrid y Ramis Barceló, R. 2012. "Un esbozo cartográfico del lulismo universitario y escolar en los Reinos Hispánicos", Cuadernos del Instituto Antonio de Nebrija de Estudios sobre la Universidad, 15/1: 61-103.

${ }^{4}$ Véase Puig, J. de. 2000a. "El "Dialogus contra lullistas", de Nicolau Eimeric, O.P. Edició i estudi”, Arxiu de textos catalans antics, 19: 75-76. 
erróneas que había encontrado en los escritos del Doctor lluminado. Josep Perarnau, después de un detallado estudio, ${ }^{5}$ indica que los artículos del Ars amativa que Eimeric atribuyó a Llull eran reelaboraciones no textuales que había hecho el inquisidor, muchas veces contrarias al pensamiento del Beato mallorquín.

La poca diligencia del Arzobispo de Tarragona obligó al pontífice a resolver el expediente en la curia papal, y se designó una comisión formada por veinte doctores en Teología para analizar veinte obras escritas en lengua vulgar que Eimeric había señalado en su Directorium de $1375 .{ }^{6}$ Eimeric compareció ante la comisión y ésta declaró sospechosos más de doscientos artículos. ${ }^{7}$ En consecuencia, la resolución del papa Gregorio XI prohibió las veinte obras de Llull presentadas por Eimeric, mediante la supuesta bula Conseruationi puritatis Catholicae fidei, en la que se exigía que todo lo relativo a Ramon Llull y a la Escuela luliana fuera recogido para someterlo a examen, y que se denunciaran las personas afines a la doctrina luliana. El profesor Perarnau ha mostrado que dicha bula era falsa y que fue inventada por el mismo Eimeric. ${ }^{8}$

El 29 de marzo de 1386 tuvo lugar, en el convento de franciscanos de Barcelona, la revisión de las proposiciones que Eimeric había extraído del Arbre de filosofia d'amor y que habían sido condenadas por la bula de Gregorio XI de 1376. La comisión, presidida por el dominico Bernat Ermengol, maestro en Teología, provincial e inquisidor, compuesta por dos dominicos y seis franciscanos, concluyó hábilmente que la bula era justa, pero que las proposiciones no se encontraban en la obra luliana. Es decir, se indicó sutilmente que Eimeric tergiversaba la realidad. De este modo, Bernat Ermengol dejaba intacta la bula Conservationi puritatis Catholicae fidei, pero salvaba la obra de Ramon Llull, acusando al inquisidor de no entenderla e, incluso, de manipularla.

En 1419, el papa Martín V otorgó al cardenal Alamanno Adimari la facultad para resolver el conflicto de la cuestión luliana: fue el 24 de marzo del mismo año cuando se promulgó en Barcelona la llamada Sententia definitiva, ${ }^{9}$ en la que se afirmaba la autenticidad del documento

5 Perarnau Espelt, J. 1997. De Ramon Llull a Nicolau Eimeric. Barcelona-Ciutat de Mallorca: Facultat de Teologia de Barcelona, Centre d'Estudis Teològics de Mallorca.

${ }^{6}$ Carreras Artau, J. y T. 1941: 32-33.

${ }^{7}$ Perarnau Espelt, J. 1997: 69-73.

${ }^{8}$ Ibidem: 110-112.

9 Véase Puig, J. de. 2000b. "La sentència definitiva de 1419 sobre l'ortodòxia lul-liana. Contextos, protagonistes, problemes", Arxiu de Textos Catalans Antics 19: 297-388. 
de Gregorio XI, aunque se declaraba que la prohibición que expresaba la bula Conservationi carecía de valor por el hecho de existir seguros indicios de haberse obtenido mediante engaños y subterfugios.

Años después, en 1483 el Rey Fernando concedió un Privilegio para fundar un Estudio General en Mallorca, con las mismas prerrogativas que tenía la Universidad de Lleida. En él profesó como primer catedrático de lulismo Pere Daguí, quien, dos años después del inicio de las lecciones, fue acusado de heterodoxia por el inquisidor dominico Guillem Caselles. ${ }^{10}$ Empezaba aquí de forma oficial un largo y tortuoso enfrentamiento entre lulistas y dominicos en Mallorca. Los Predicadores se amparaban en la condena que hizo de Llull el papa Gregorio XI, a instancias del inquisidor Nicolau Eimeric. Pese a ser una flagrante manipulación del autor del Directorium Inquisitorum, conocida ya en el siglo $\mathrm{XV},{ }^{11}$ los dominicos se aferraron a ella para boicotear tanto el lulismo como los progresos del Estudio General Luliano.

Daguí tuvo que defenderse en contra del Inquisidor de Aragón y tuvo que exponer la ortodoxia de sus trabajos en Roma. Asimismo, el Rey Fernando intercedió a su favor y la Santa Sede proclamó la ortodoxia de los escritos de Daguí. ${ }^{12}$ El maestro catalán aprovechó para ejercer su magisterio en la corte itinerante de los monarcas católicos, impregnando de lulismo los lugares que visitaba. ${ }^{13}$ En concreto, influyó mucho en el cardenal Cisneros quien, desde entonces, fue un devoto Iuliano.

El interés por Llull crecía y los dominicos contraatacaron reimprimiendo el Directorium en 1503. Uno de los primeros frutos de esta embestida antiluliana pudo verse en 1505, cuando en el Colegio de Santa María de Jesús de Sevilla se prohibió la enseñanza del nominalismo y del lulismo en sus estatutos, ${ }^{14}$ a causa del desfavorable concepto que tenía del lulismo y del nominalismo Rodrigo de Santaella,

${ }^{10}$ Pérez Martínez, L. 1960. "El maestro Daguí y el lulismo mallorquín de fines del siglo XV, Estudios Lulianos, 4: 291 y ss.

11 Véanse los trabajos recopilados en Muzzi, S. (ed.) 2010. Da Raimondo Lullo a Nicola Eimeric. Storia di una falsificazione testuale e dottrinale. Roma: Antonianum.

12 Véase Ramis Barceló, R. 2013a. "En torno al escoto-lulismo de Pere Daguí", Medievalia 16: 235-264.

${ }^{13}$ Santamaría, A., 1983. La promoción universitaria en Mallorca: 96-116. Palma: Annex.

14 AHUS, Legajo 0608-21, Constitutionis Collegii Maioris Sanctae Maria de Iesu, Studi Generalis et Studi Hispalensis, Sevilla, 1701, f. 26. 
fundador de la Universidad de Sevilla. ${ }^{15}$ Sevilla había sido un gran centro luliano hasta finales del XV. Parece ser que poco después, el primer Rector del Colegio, el canónigo Martín Navarro, eliminó estas durísimas interdicciones, ${ }^{16}$ aunque no se conoce el alcance del lulismo en Sevilla en la época posterior.

No obstante lo anterior, Cisneros llamó a Nicolau de Pacs, que había sido profesor en el Estudio General Luliano, a regentar una cátedra de lulismo en Alcalá en 1508. ${ }^{17}$ La conexión del Estudio General Luliano con la Universidad no sólo vinculó a Nicolau de Pacs, sino también en 1565 al catedrático mallorquín Francesc Riera, que fue invitado a Alcalá para impartir un curso de lulismo, que dio lugar a ciertos problemas ideológicos. ${ }^{18}$ También Dimas de Miguel, con el beneplácito de Felipe II, intentó que se dictase un curso de lulismo a finales del XVI, tal y como se verá en la documentación que aquí se expone. ${ }^{19}$

La universidad alcalaína adquirió rápidamente un gran prestigio y sirvió de trampolín para la propagación del lulismo en la Corte castellana. La influencia luliana en Felipe II fue muy amplia y abarcó prácticamente todas las facetas del polígrafo mallorquín, pese a que no han sido estudiadas con exhaustividad, a saber: como santo, como sabio y como apologeta de la religión cristiana. ${ }^{20}$ No debe pasar por alto el esfuerzo regio para favorecer la canonización de Llull. Todo lo relacionado con él (incluso el Pseudo-Llull, que a la sazón no estaba separado de las obras auténticas) le llevó a un estudio del Arte, de las matemáticas e incluso de la alquimia.

El monarca instituyó la Academia de Matemáticas en Madrid, fundada por Juan de Herrera. En ella, el lulismo lógico-matemático representaba una parte relevante del plan de estudios. Herrera intentó infundir en dicha Academia un lulismo de carácter matemático, presente también en los proyectos arquitectónicos que diseñó personalmente. ${ }^{21}$

15 Copio de Beltrán de Heredia, V. 1973. "La teología en nuestras universidades del Siglo de Oro", en Miscelanea Beltrán de Heredia, t. IV: 447448. Salamanca: San Esteban.

${ }_{16}$ Véase Serrera Contreras, R. M. y Sánchez Mantero, R., 2005. La Universidad de Sevilla, 1505-2005: 146. Sevilla: Universidad de Sevilla.

17 Trias Mercant, S. 1985. Història del pensament a Mallorca: 140-143, I, Palma: Moll.

${ }^{18}$ Pinto Crespo, V. 1982: 304.

${ }^{19}$ AHN, Consejo de la Inquisición, L. 970, f. 444 (antigua numeración, f. 436).

${ }^{20}$ Pérez Martínez, L. 1962: 193-249.

${ }^{21}$ Wilkinson-Zerner, C. 1993. Juan de Herrera, Architect to Philip II of Spain: 42-45. New Haven/Londres: Yale University Press. 
Los textos lulianos para dicha academia fueron redactados por Pedro de Guevara, entre los que destaca el Arte general y breve. ${ }^{22}$

En Alcalá se centralizó durante esta centuria no sólo la difusión de las doctrinas lulianas, sino también la defensa apologética de Llull para poder iniciar los trámites del proceso de beatificación. Éste debía confirmar el culto que le tributaban en Mallorca y contrarrestar el afán de la Orden de Predicadores, que quería incluir a Llull en el Índice de Libros Prohibidos. ${ }^{23}$ En 1580 el dominico Fray Hernando del Castillo canalizó unas denuncias antilulianas procedentes de la Universidad de Valladolid, ${ }^{24}$ que la Inquisición manejó, aunque no llegaron a cristalizar en una prohibición.

El Directorium, como es sabido, fue reimpreso en numerosas ocasiones a finales del XVI y comienzos del XVII, de manera que todos los inquisidores tuvieron que topar con la bula de Gregorio XI al afrontar el estudio de Llull. La Santa Sede jamás declaró falsa la bula, pese a las continuas peticiones regias, de modo que continuó apareciendo en cada reimpresión. ${ }^{25}$ Ello contribuyó a crear un clima de hostilidad y prevención hacia los defensores del lulismo, que tenían que "invertir la carga de la prueba".

Tal y como han estudiado muy bien Lorenzo Pérez y Virgilio Pinto, los esfuerzos de Felipe II para lograr la canonización de Ramon Llull sirvieron para que Clemente VIII, no muy inclinado hacia Llull, no incluyese al Doctor lluminado en el Índice ${ }^{26}$ y que diera las letras compulsoriales ${ }^{27}$ para que los Jurados de la Ciudad y Reino de Mallorca pudiesen recoger los testimonios favorables a la doctrina luliana. ${ }^{28} \mathrm{La}$ situación no resultaba cómoda en la Santa Sede, pues en esos mismos

22 Guevara, P. 1584. Arte general y breve, en dos instrumentos, para todas las ciencias. Recopilada del Arte magna y del Arbor scientiæ del doctor Raymundo Lulio. Madrid: Herederos de Alonso Gómez.

${ }^{23}$ Pinto Crespo, V. 1982: 293-314.

24 Ibidem: 309-310. Sobre el lulismo en la Universidad de Valladolid hay todavía mucho que investigar. Según Andrés, M., 1976. La teología española en el siglo XVI: 294. Vol. I. Madrid: BAC, el lulismo estaba de moda en Valladolid ya a finales del XV, como atestiguan algunas impresiones de obras de Llull que se hicieron en esa ciudad y otros textos manuscritos, hoy albergados en diferentes bibliotecas.

${ }^{25}$ Pérez Martínez, L. 1989: 730-731.

${ }^{26}$ Pinto Crespo, V. 1982: 297-312.

27 ADM, Causa Pía Luliana, Materiales recogidos para probar el culto inmemorial, ff. 200-206v.

${ }^{28}$ Pérez Martínez, L. 1962: 219. 
años fue condenado Giordano Bruno, ${ }^{29}$ acusado -literalmente- de haber poseído libros de autores prohibidos como Ramon Llull.

En la labor apologética a favor de Llull se involucraron en el último tercio de la centuria, por petición directa del monarca, algunos catedráticos que enseñaban dotrinas lulianas, como Joan-Lluís Vileta (en Barcelona) o Antoni Bellver (en Palma). Las gestiones fueron llevadas a cabo por Juan Arias de Loyola. Felipe II mandó recopilar todas las obras de Llull y hacer un catálogo exhaustivo de las mismas: de esa labor se encargó principalmente el catedrático Antonio Bellver. ${ }^{30}$ Ordenó asimismo nutrir de títulos lulianos la Biblioteca del Escorial. Dicha labor fue llevada a cabo por Dimas de Miguel, arcediano de la Catedral de Barcelona y discípulo de Vileta. Del doctor Dimas de Miguel debe subrayarse que fue un activo lulista en el círculo de Alcalá y que influyó mucho en Juan de Herrera. Algunas fuentes indican que en 1586 enseñaba lulismo en Valencia. ${ }^{31}$ Los últimos años de su vida los pasó en Roma, donde leyó en su casa la obra de Ramon Llull.

\section{LA INQUISICIÓN Y EL LULISMO EN LA PRIMERA DÉCADA DEL SIGLO XVII}

En los Reinos Hispánicos la situación era particularmente peligrosa, ya que el lulismo, gracias a la insistencia de la Inquisición, fue asociado a ambientes heréticos. Muerto Felipe II, el Santo Oficio, se sintió más libre para condenar obras que consideraba doctrinalmente peligrosas. ${ }^{32}$ Desde Roma, siguiendo las directrices tridentinas, se propagó un esfuerzo unificador sobre la base del tomismo, que poco a poco iría penetrando en todas las universidades peninsulares, mientras que el lulismo se continuaría profesando en el Estudio General de Mallorca.

En Mallorca, el lulismo universitario estaba tutelado por el Gran $i$ General Consell y por los Jurados, de manera que revestía un carácter jurídico-político. ${ }^{33}$ El 22 de noviembre de 1604, el Gran $i$ General Consell nombró Síndico de la Causa en Mallorca al notario Pere Ribot, ${ }^{34}$ un hombre que podía reunir y autentificar todos los papeles necesarios. Sus

${ }^{29}$ Mercanti, A. 1961. Il sommario del proceso di Giordano Bruno: 106. Città del Vaticano: Biblioteca Apostolica Vaticana.

30 Trias Mercant, S. 1985: 143-144.

${ }^{31}$ Pérez Martínez, L. 1962: 196.

32 Pérez Martínez, L. 1989: 735-737.

33 Ramis Barceló, R. 2010. "El lul-lisme i l'antilul-lisme dels juristes mallorquins als segles XVII i XVIII" Studia Lulliana 50: 75-78.

34 ARM, Extraordinaris del Gran i General Consell, f. 258. Pérez Martínez, L. 1961: 110-112. 
tareas se concretaban en tres grandes frentes: la recopilación y publicación de documentos lulianos y procesales anteriores a 1604; la defensa de Llull en escritos apologéticos y cartas; y, finalmente la preparación y ejecución del primer proceso diocesano de beatificación. Ribot hizo publicar la Sentencia Definitiva de 1419, importante trámite documental para saber exactamente de qué se acusaba a Llull y para anular los efectos canónicos de bula de Gregorio XI. ${ }^{35}$

El día 2 de Junio de 1610 los Jurados decidieron que Antonio Busquets, franciscano, fuera nombrado Síndico de asuntos lulianos en Roma, con una dotación de 200 ducados y con dedicación exclusiva. ${ }^{36}$ Para que Busquets se pudiera llevar a Roma una documentación adecuada, los Jurados suplicaron al Obispo que iniciara un proceso formal y ordinario sobre la vida, costumbres y milagros de Ramon Llull.

Por otra parte, paralelamente a la elección de Antonio Busquets el mismo día 2 de junio de 1610 se nombró una comisión de catorce personas. ${ }^{37}$ Aquí comenzó definitivamente la Causa Pía, que tendría el mismo poder jurídico de que gozaban los Jurados en el Gran i General Consell en lo que respecta a los temas de la protección y tutela del proceso. Ribot hizo adjuntar los privilegios favorables a la doctrina luliana que habían recopilado los Jurados y que se guardaban en la sede del Gran i General Consell. ${ }^{38}$

Paralelamente a la tarea notarial y procesal de Ribot, el día 30 de julio de 1615 los canónigos Guillem Custurer y Antoni Gual ${ }^{39}$ recibieron la autorización de los Jurados para predicar y suscitar la devoción del pueblo a fin de recibir limosnas. La Causa Pía se empezó a mover en dos frentes: recopilación, clasificación y autenticación de las obras y de los testigos, encargada a los notarios y a los canonistas, y en la recaudación de fondos para la causa luliana, de la que se ocupaban habitualmente los canonistas y los teólogos. Se encontraba asimismo en Roma, como mínimo desde 1600, el teólogo Pedro Jerónimo Sánchez de Lizárazu, a quien Felipe III le había encomendado la defensa de Llull.

35 Pérez Martínez, L. 1989: 742.

${ }^{36}$ ADM, Copia hecha en el siglo XVIII del primer proceso (1605-1613) y del tercero (1751), f. 200v.

${ }^{37}$ Pérez Martínez, L. 1970. Los jurados de Mallorca y la Institución de la Causa Pía Luliana: 9-10. Palma: Ajuntament de Palma.

38 ADM, Causa Pía Luliana, Materiales recogidos para probar el culto inmemorial, ff. 49-52.

39 ARM, Fondo luliano, 57. En el documento se cita a Antoni Gil, pero todo apunta a que era el canónigo Antonio Gual. 
Los primeros enfrentamientos ocurrieron ya en la primera década de la centuria. En 1604 el Inquisidor de Pavía mandó al Santo Oficio una obra de Alfonso de Proaza, insigne lulista. ${ }^{40}$ Ese mismo año, el secretario del Papa y de la Congregación de la Inquisición escribió al Obispo de Barcelona ordenando "que no se permitiera leer y disputar acerca de la doctrina de Llull y que se notificara el decreto a los doctores del Estudio General". ${ }^{41}$ Tal final hace suponer un largo declinar del lulismo a finales del XVI, que conllevó la extinción de la Escuela Luliana barcelonesa y del Iulismo universitario en la Ciudad Condal.

La fuerza de las prohibiciones muestra también la relevancia de dichos núcleos y la penetración del Arte de Llull en diferentes puntos de la Península. Se puede añadir que en estas fechas unos aragoneses presentes en el Colegio Español de Bolonia, tal y como documenta Pérez Martínez, instruyeron al intrépido Placido Perilli, un religioso celestino, en la obra luliana. ${ }^{42}$ Gracias a una carta que Placido remitió a los Jurados de Mallorca se sabe que el lulismo en la Universidad de Bolonia se había vuelto una doctrina problemática y que los libreros no querían expender sus libros. En el Colegio Español, nadie sabía nada de Llull salvo Antonio Lorenzo de Quintaniella, que le mostró algunos libros lulianos en la Biblioteca del Colegio, y el doctor Jerónimo Arbitius, natural de Daroca, que le instruyó en la doctrina Iuliana. ${ }^{43}$

En 1606 el Inquisidor de Mallorca detuvo la impresión de la Apología del Doctor Bellver y delató a la Suprema una Vida y hechos del admirable doctor y mártir Ramon Llull que había escrito su discípulo Juan Segui. ${ }^{44}$ La inquina antiluliana del Inquisidor Juan Gutiérrez Flores queda patente en el secuestro de diversas obras lulianas. ${ }^{45}$ Calificó la obra de Bellver el jesuita Esteban de Ojeda, quien mostró su disconformidad con las doctrinas lulianas, pese a comentar que estuvo tentado a estudiarlas en Alcalá con el Doctor Dimas de Miguel. ${ }^{46}$

Paralelamente, el Inquisidor de Mallorca llamó a declarar a todos los que habían intervenido en la edición de la Apología de Bellver. Entre los que pasaron a declarar se encontraban algunos destacados lulistas, como los jesuitas Joan Torrents y Andreu Moragues, o el ya citado

40 Pérez Martínez, L. 1961: 238.

${ }^{41}$ Copio de Fernández Luzón, A. 2005. La Universidad de Barcelona en el siglo XVI: 232. Barcelona: Edicions de la Universitat de Barcelona.

42 Pérez Martínez, L. 1989: 738-739.

${ }^{43}$ BBM, A. Muntaner, Observata a variis auctoribus de B. Raymundo Lull Majoricensis (sic) martiri bene loquentibus... [manuscrito], ff. 172v-173v.

${ }^{44}$ AHN, Consejo de la Inquisición, L. 847, f. 79.

${ }^{45}$ Pérez Martínez, L. 1989: 744.

${ }^{46}$ AHN, Consejo de la Inquisición, L. 847, f. $121 \mathrm{v}$. 
notario Pere Ribot. ${ }^{47}$ Al final, la Suprema, en 1611, a la vista de la documentación enviada, decidió devolver todos los libros a sus propietarios y zanjaron así el asunto. ${ }^{48}$

Nótese que, desde la muerte de Felipe II hasta 1612, año en el que formalmente empezó el proceso diocesano de beatificación de Llull, las posturas frente al lulismo fueron tan enconadas como extremadas. La Inquisición no dejaba de hostigar al lulismo en los diferentes puntos de la Monarquía Hispana, mientras que la Diócesis de Mallorca y Felipe III intentaban una vez más que Ramon Llull fuese elevado a los altares. Mientras el lulismo, por culpa de la persecución inquisitorial, empezaba a declinar en algunas universidades, en otras, como Alcalá y Mallorca, continuaba aún con fuerza.

\section{LA FIGURA Y LA OBRA DE AGUSTÍN NÚÑEZ DELGADILLO}

Uno de los predicadores y lulistas más eximios que vivió este convulso período a caballo entre el XVI y el XVII fue Fray Agustín Núñez Delgadillo. ${ }^{49}$ Natural de Cabra (Córdoba), donde nació en $1571,{ }^{50}$ a los 16 años solicitó el hábito carmelita en el Convento de Nuestra Señora de la Cabeza de Granada, ciudad de donde era su madre Doña María Núñez de Ovando, emparentada -aunque lejanamente- con Santa Teresa de Jesús. En aquel convento cursó sus estudios de Gramática y Retórica, para más tarde estudiar Súmulas y Lógica con el célebre P. Maestro Diego Ruiz.

Según Rodríguez Marín, alcanzó el grado de bachiller en la Facultad de Artes de la Universidad de Osuna en 1591, se licenció el 16 de enero de 1593 y se graduó de Maestro el día siguiente. ${ }^{51}$ Con solo 20 años logró alcanzar la cátedra de Artes en esa Universidad, siendo allí "universalmente aclamado". ${ }^{52}$ Al parecer, empezó los estudios de Teología en el Colegio de San Alberto de Sevilla. ${ }^{53}$ Resulta difícil seguir con precisión su vida, pero se sabe que en 1609 tomó parte en la famosa

${ }^{47}$ Pérez Martínez, L. 1989: 744-749.

${ }^{48} \mathrm{AHN}$, Consejo de la Inquisición, L. 847, f. 94.

49 Abundantes elogios sobre su vida, escritos poco tiempo después de su fallecimiento, pueden verse en la clásica obra de Alegre de Casanate, M. A. 1639. Paradisus Carmelitici decoris: 498-500. Lugduni: lacobi \& Petri Prost.

${ }^{50}$ Barea López, O. 2012. Heráldica y genealogía de Cabra de Córdoba, Doña Mencía y Monturque y de sus enlaces (ss. XV-XIX), II: 52. Bubok Publishing.

51 Rodríguez Marín, F., 1889. Apuntes y documentos para la historia de Osuna: 791-792. Osuna: Imprenta de M. Ledesma Vidal.

52 Rodríguez Carretero, M. 2000. Epítome historial de los Carmelitas de Andalucía y del Reino de Granada: 264. Sevilla: Grafisur.

${ }^{53}$ Idem. 
controversia De auxiliis, junto con el Cardenal Bellarmino y el $\mathrm{P}$. Francisco Suárez, y que recibió el grado de Doctor en la Ciudad Eterna. ${ }^{54}$ Se ha dicho que fue predicador real y se sabe que murió en Madrid en julio de 1630 con gran fama de santidad. ${ }^{55}$

Gonzalo Díaz señala que "profesó las doctrinas lulistas, que trató de difundir a través de su labor de cátedra, consiguiendo incluso durante su paso por la Universidad de Zaragoza que se proveyera una cátedra de lulismo". ${ }^{56}$ Otros autores, siguiendo a Nicolás Antonio, ${ }^{57}$ dicen que instituyeron en dicha Universidad una cátedra sólo para él. ${ }^{58}$ No creo que se tratase de una cátedra de lulismo, ${ }^{59}$ sino que aprovechó su cátedra para leer un curso sobre el Arte de Llull. Indica también Gonzalo Díaz, ${ }^{60}$ siguiendo de nuevo a Nicolás Antonio, ${ }^{61}$ que también ocupó cátedras en las Universidades de Córdoba, Granada, Valencia y Alcalá, un dato que parece exagerado. Todo apunta a que, después de su estadía en Zaragoza, pasó a Granada, donde consta que fue Lector de Prima y Regente de Estudios en su convento. ${ }^{62}$

En la Facultad de Teología de la incipiente Universidad de Zaragoza había a la sazón cuatro cátedras de Teología escolástica (Prima, Vísperas, Santo Tomás y Durando) y una de Sagrada Escritura. ${ }^{63}$ En los documentos de la época se indica que Núñez Delgadillo era catedrático de Teología escolástica, ${ }^{64}$ un dato que no aclara la opinión

${ }^{54}$ Martínez Carretero, I. 2009. Los Carmelitas en Sevilla. 650 años de presencia (1358-2008): 273-276. Sevilla: Provincia Bética de PP. Carmelitas.

55 Velasco Bayón, B. 1954. Historia del Carmelo español: Provincias de Cataluña y Aragón y Valencia, 1563-1835: 445. Roma: Institutum Carmelitanum.

${ }^{56}$ Díaz Díaz, G. 1995. Hombres y documentos de la filosofía española, vol. 5: 842. Madrid: CSIC.

${ }^{57}$ Antonio, N. 1783. Bibliotheca hispana, vol. 1.: 177. Madrid: Joaquín de Ibarra.

${ }^{58}$ Garrido, P. M. 1982. Santa Teresa, San Juan de la Cruz y los carmelitas españoles: 98. Salamanca: Universidad Pontificia de Salamanca.

${ }^{59}$ Ramis Barceló, R. 2012: 86.

${ }^{60}$ Díaz Díaz, G. 1995: 841-843.

${ }^{61}$ Antonio, N. 1783: 177.

62 Núñez Delgadillo, A. 1617. Sermon de la gloriosa Sancta Teresa de lesvs, predicado en el Conuento de las Carmelitas Descalças de Granada, Lunes de su octaua. Por el Padre Maestro Fray Augustin Nuñez Delgadillo, Carmelita Lector de prima de Theologia, y Regente de los estudios en el Conuento de Nra. Señora de la Cabeça de la mesma Ciudad. Granada, imprenta de Juan Muñoz.

63 Jiménez Catalán, M. y Sinués y Urbiola, J. 1924. Historia de la Real y Pontificia Universidad de Zaragoza: 12. Zaragoza: Tipografía La Académica.

${ }^{64}$ Núñez Delgadillo, A. 1629. Minas celestiales descrbiertas en los evangelios de qvaresma destribvidas en sermones. por el padre maestro fray 
que profesaba. ${ }^{65}$ Margarita Alvar indica que, en las exequias y certamen por la muerte de la reina Margarita de Austria, ocurrida en 1611, "celebró la misa y predicó el Padre Maestro fray Agustín Núñez Delgadillo, catedrático de Scoto". ${ }^{66}$ No parece probable, puesto que la cátedra de Escoto de la Universidad de Zaragoza, fue -al parecer- de filosofía y se instituyó en $1691 .^{67}$

Entre la documentación inquisitorial, como se verá, se indica que Delgadillo leía De Trinitate ${ }^{68}$, aunque ello no aclara exactamente qué cátedra poseía. Parece plausible la tesis de Inocencio de Camón, quien, con datos de la contaduría, sostiene que poseyó la cátedra de Durando, como mínimo en $1612 .{ }^{69}$ Con todo, se trata de una situación confusa y, desde luego, en la documentación del fondo de la Inquisición no arroja demasiada luz sobre el asunto.

Por fortuna, en la documentación inquisitorial, tan inexacta en ciertos aspectos, ha permanecido una copia del curso ${ }^{70}$ sobre el Arte de Llull que dictó el maestro Núñez Delgadillo en 1610, que fue examinado por los calificadores. En él se muestra el entusiasmo por el Doctor lluminado, que -por mor de la Inquisición- tuvo que reprimir durante la parte final de su estancia en Zaragoza, aunque pudo retomarlo en Granada y en Madrid. El curso sobre el Arte muestra que Núñez Delgadillo no sólo se incardinaba en la tendencia lógico-enciclopédica, ${ }^{71}$ sino que también se situaba en toda una tradición del estudio del Arte de

Agustin Nuñez Delgadillo de la Orden de nuestra Señora del Carmen de la Obseruancia, antes Catedrático propietario de Teologia Escolástica en la Universidad de Zaragoca, y aora Predicador del convento de nuestra del Carmen de Madrid, Corte de su Magestad, Madrid: Viuda de Luis Sánchez.

65 Jiménez Catalán, M. y Sinués y Urbiola, J. 1924: 243, indicaron que "los Predicadores, la Religión de San Agustín, Franciscanos, Mercedarios, Trinitarios y del Carmen calzado, fueron las órdenes religiosas que, en cuanto a nuestro Estudio general, podemos denominar como propiamente universitarias".

${ }^{66}$ Alvar. E., 1980. "Exequias y certamen poético por Margarita de Austria (Zaragoza, 1612)". Archivo de filología aragonesa, 26-27: 232.

67 Jiménez Catalán, M. y Sinués y Urbiola, J. 1924: 266. $437 v)$.

${ }^{68}$ AHN, Consejo de la Inquisición, L. 970, f. 445v (antigua numeración, f.

${ }^{69}$ Camón y Tramullas, I. 1768. Memorias literarias de Zaragoza: 68-69. Zaragoza: F. Moreno.

${ }^{70}$ AHN, Consejo de la Inquisición, L. 970, ff. 449-455 (antigua numeración, ff. 442-447). No se estudiará detenidamente el contenido del curso, pues exigiría un espacio mucho mayor del que aquí se requiere.

71 Trias Mercant, S. 2009. Diccionari d'escriptors Iul-listes: 303. UIB-UB, Palma-Barcelona. 
Llull presente tanto en los Reinos Hispánicos como en Francia, en las ciudades italianas y en el Sacro Imperio.

Sin embargo, el maestro Delgadillo no sólo tuvo problemas con la Inquisición en Zaragoza en 1610, sino que también tuvo muchas delaciones ${ }^{72}$ su obra Artificio breve y muy claro para discurrir sin mucho estudio, y con superioridad en toda materia de costumbres, ${ }^{73}$ que al parecer había circulado como "pliego de papel solo" en Granada y en Sevilla. La técnica definida por los calificadores como "cierto artificio para saber toda la Theologia escolastica y mistica" ${ }^{74}$ consistía en tomar cien palabras y establecer combinaciones entre ellas para que con ello se perfeccionase la técnica de la memoria y se lograra una manera sencilla de discurrir.

Su obra Breve y fácil declaración del artificio luliano ${ }^{75}$ es una muestra elocuente de esta voluntad de disponer el lulismo en forma lógica y retórica, según las modas que tan en boga estaban en Francia a la sazón. ${ }^{76}$ También consta por el testimonio de Sebastián Izquierdo ${ }^{77}$ en su Pharus Scientiarum ${ }^{78}$ que compuso una Tabla para predicadores, con la que pretendía aplicar las excelencias del Arte luliano a la oratoria sagrada. Estaba compuesta de veinte cuestiones y cien términos que el predicador debía memorizar para hacer un uso más correcto y ágil de los mismos. El propio Izquierdo se refirió también a un discípulo del maestro Delgadillo, el licenciado Miguel de Vargas, quien publicó, tiempo después en Madrid, una obrita para dar difusión a la Tabla de su maestro. ${ }^{79}$

${ }^{72}$ AHN, legajo 4444, núm. 45, f. $1 \mathrm{v}$.

73 1627. Cuenca: Domingo de la Iglesia.

$74 \mathrm{AHN}$, legajo 4444, núm. 45, f. $1 \mathrm{v}$.

75 Núñez Delgadillo. 1624. Alcalá: Juan Gracián.

${ }^{76}$ Carreras Artau, J. y T. 1941: 293-295.

77 Fuertes Herreros, J. L. 1981. La lógica como fundamentación del arte general del saber en Sebastián Izquierdo: estudio del "Pharus scientiarum" (1659): 245. Salamanca: Universidad de Salamanca, indica que "Izquierdo habla de este carmelita con una especial simpatía, como si les uniera algún vínculo de amistad".

${ }^{78}$ Izquierdo, S., 1659. Pharus scientiarum: 283. Lugduni, C. Bourgeat [et] M. Lietard.

${ }^{79}$ Vargas, M. de. 1658. Tesoro de la memoria y del entendimiento y arte facil y breue para toda sabiduría, Madrid: Imprenta Real, 1658. 


\section{PETICIÓN AL FISCAL DEL SANTO OFICIO (1610)}

El 14 de diciembre de $1610,{ }^{80}$ Fr. Miguel Santos de San Pedro ${ }^{81}$ y el licenciado Gaspar de Peralta, Inquisidores de Aragón, mandaron a la Suprema un expediente que contenía las calificaciones contra la lectura que Agustín Núñez Delgadillo había hecho del Arte parba et magna de Ramon Llull. Según decían, "desseamos saber si este autor es catholico y su doctrina tal que se pueda leher y ansi nos ynformaran de todo lo que debemos ser informados". 82

Se adjuntaba, en primer lugar, la calificación del Doctor Domingo García, ${ }^{83}$ canónigo del Pilar y catedrático de la Universidad, quien se reveló como un acérrimo antilulista. En su informe, el Dr. García calificó las diferentes proposiciones de la lectura del Maestro Delgadillo, apoyándose en Eimeric y en la supuesta condena de Gregorio XI. Las diferentes proposiciones fueron calificadas negativamente. Una de ellas, por ejemplo, fue considerada "timeraria, injuriosa, escandalosa, impia et erronia". ${ }^{84}$

Las calificaciones hechas por dos dominicos, Fray Gaspar Luis Serra y Fray Antonio Bielsa, ambos presentados de la Orden, eran una mera repetición de las ideas del Directorium de Eimeric. ${ }^{85}$ La sucinta calificación hecha por los padres agustinos Fray Gerónimo de Aldobera y Monsalbe y Fray Felipe Hernández de Monreal, ${ }^{86}$ ambos catedráticos de la Universidad y compañeros de Núñez Delgadillo en la Facultad de Teología, indicaba que, pese a que los mallorquines tenían a Llull por Santo, y que Luis de Paramo en el tomo ${ }^{87}$ así como otros autores 425).

${ }^{80}$ AHN, Consejo de la Inquisición, L. 970, f. 433 (antigua numeración, f.

${ }^{81}$ Fue inquisidor de Aragón desde 1604 a 1621. Véase Sarrión, A. 2006. Médicos e Inquisición en el Siglo XVII: 198. Cuenca: Universidad de Castilla-La Mancha. 433).

${ }^{82}$ AHN, Consejo de la Inquisición, L. 970, f. 441 (antigua numeración, f.

83 Sobre Domingo García, véase Polo Carrasco, J. 1984. "Los juramentos inmaculistas de la Universidad, Cabildo Catedralicio y Ciudad de Zaragoza (1617-1619)". Cuadernos de historia Jerónimo Zurita, 49-50 (1984): 105 . 426).

${ }^{84}$ AHN, Consejo de la Inquisición, L. 970, f. 434 (antigua numeración, f.

85 AHN, Consejo de la Inquisición, L. 970, ff. 437-438 (antigua numeración, ff. 429-430).

${ }^{86}$ Sobre ambos, véase Camón y Tramullas, I., 1768: 30 y 41.

${ }^{87}$ Se refiere a Luis de Páramo, historiador de la Inquisición. Su juicio favorable a Llull fue recogido y comentado por Gabriel Vázquez antes de que 
graves tenían su doctrina por católica, ellos consideraban que "en algunas partes y proposiciones no se le puede defender y que es justo mandar no se lea y no se enseñe". ${ }^{88}$ Agregaban que hacía unos cinco años que el Obispo de Barcelona había recibido del Papa unas letras en las que mandaba que no se enseñase la doctrina luliana.

El expediente adjuntaba asimismo un informe ${ }^{89}$ del Dr. García, quien ponía en antecedentes a los Inquisidores acerca de la figura de Ramon Llull. En él repetía los tópicos de Eimeric y añadía algunos datos de interés. Subrayó que la doctrina luliana era fruto de la iluminación que Llull tuvo en Randa, al tiempo que explicó todas las exageraciones de los lulistas, fruto de una lectura literal del optimismo con el que Llull concluía sus obras: era, al decir del Dr. García, una doctrina que se tildaba a sí misma de mejor que las demás, capaz de solucionar todos los problemas y de aprenderse en cuestión de pocas horas.

El informe del Dr. García vinculaba el lulismo de su época con el del siglo XIV, que, según la descripción de Eimeric, estaba teñido de apocalipticismo y de obcecación excluyente. Contra ello, como puede verse en el documento, las palabras de San Agustín y de San Pablo sobre el saber resultaban un buen remedio. Informaba también que en las Universidades mayores no se explicaba el lulismo, salvo en Alcalá, donde hacia 1586, por instancia de Dimas de Miguel y con la protección de Felipe II se explicaron las doctrinas lulianas por espacio de un mes y contaron con la oposición de todo el profesorado.

El Promotor Fiscal de la fe, Pedro Fernández de Cea, ${ }^{90}$ señaló en su declaración ${ }^{91}$ las inconveniencias de leer a Ramon Llull, afirmando que en Salamanca y en Alcalá no se había leído a este autor ${ }^{92}$ y que "es de mucho peligro el començar a introducir su doctrina en esta universidad donde tenemos por vecinos a muchos herejes de françia, y de otras partes infectas". ${ }^{93}$ Como muy bien señala Virgilio Pinto, la

se publicase la propia obra de Páramo. Véase Vázquez, G. 1598. Opera Theologica Omnia: 197. Compluti, Ex officina Ioannis Gratiani. 433).

${ }^{88}$ AHN, Consejo de la Inquisición, L. 970, f. 441 (antigua numeración, f.

89 AHN, Consejo de la Inquisición, L. 970, ff. 443-444 (antigua numeración, ff. 435-436) = Documento I.

${ }^{90}$ Sobre Fernández de Cea, véase Contreras, J. 1982. El Santo Oficio de la Inquisición de Galicia: 217. Madrid: Akal.

91 AHN, Consejo de la Inquisición, L. 970, ff. 439-440 (antigua numeración, ff. 431-432) = Documento II.

${ }^{92}$ Es una afirmación inexacta, como se ha podido ver antes. Véase Ramis Barceló, R. 2012: 87. 431v).

${ }^{93}$ AHN, Consejo de la Inquisición, L. 970, f. 439v (antigua numeración, f. 
petición del Fiscal ponía de manifiesto la acogida favorable de la doctrina de Llull en Zaragoza, la difusión de los argumentos de los detractores de Llull y el ambiente de temor y rigor frente a la herejía. ${ }^{94}$

En el examen de testigos, se examinó en Audiencia de mañana, el día 4 de diciembre, a un joven estudiante llamado Pedro Lared, ${ }^{95}$ de diecinueve años. Se le preguntó con qué maestros estudiaba y respondió que oía a [Gabriel] Romeo ${ }^{96}$ de la Orden de la Merced, quien leía la cátedra de Prima; a Felipe Hernández que leía de bonitate et malicia humanum actuum; al P. Ripol, de la Orden del Carmen; ${ }^{97}$ al P. Aldovera, de la Orden de San Agustín; y al P. Delgadillo que leía De Trinitate. ${ }^{98}$

El estudiante indicó asimismo que quince días antes el Maestro Delgadillo leyó el "Arte Parba et Magna" de Ramon Llull. La leía "acavada la Lection de obligacion de quatro a cinco y la dejo de leer por mandato del Rector y del claustro". ${ }^{99}$ Se trataba, por lo tanto, de una doctrina extraoficial, que generaba, al parecer, gran interés en los estudiantes. No se puede saber si tal explicación estaba vinculada con la teología escolástica que tenía que enseñar. El propio alumno proporcionó un breve resumen de la explicación de Núñez Delgadillo, que se correspondía con el cuadernillo de la explicación del Arte que se encuentra entre la documentación inquisitorial.

La deposición del estudiante explicaba también la discusión que tuvo el maestro Delgadillo con una persona que le increpó en las inmediaciones del aula por haber leído a Ramon Llull. Ciertamente, el contertulio de Delgadillo se basaba en el testimonio de Eimeric y en la bula de Gregorio XI, mientras que el carmelita hacía referencia a las aprobaciones que había tenido la doctrina de Llull, que había recibido protección apostólica ${ }^{100} \mathrm{e}$ incluso privilegios de un Rey de Aragón. ${ }^{101}$

${ }^{94}$ Pinto Crespo. V. 1982: 313.

${ }^{95} \mathrm{AHN}$, Consejo de la Inquisición, L. 970, f. 445 (antigua numeración, f. 437).

96 Sobre Gabriel Romeo, Camón y Tramullas, I. 1768: 32.

97 Se trata de Miguel Ripol de Atienza, véase Camón y Tramullas, I. 1768: 69.

${ }^{98} \mathrm{AHN}$, Consejo de la Inquisición, L. 970, f. 445v (antigua numeración, f. 437v).

${ }^{99} \mathrm{AHN}$, Consejo de la Inquisición, L. 970, f. 445v (antigua numeración, f. 437v).

${ }^{100}$ AHN, Consejo de la Inquisición, L. 970, f. 434 (antigua numeración, f. 426), esta idea fue calificada por el Dr. García como falsa, aunque en aquel momento en Mallorca y en buena parte de la Península se estaban recogiendo los testimonios favorables, que incluían la Sentencia Definitiva de 1419. f. $439 v)$.

${ }^{101} \mathrm{AHN}$, Consejo de la Inquisición, L. 970, f. 447v (antigua numeración, 
Señalaba también el estudiante Pedro Lared que muchos alumnos habían participado de la lección del maestro Delgadillo, quien había intentado deshacer los tópicos de Eimeric y presentar una lectura simplificada del Arte de Llull, apta para su aprendizaje en poco tiempo.

Realmente, los argumentos de los antilulistas se basaban en dos ideas muy diferentes. La primera, que las obras de Llull habían sido prohibidas por la bula de Gregorio XI y que en el Directorium de Eimeric se hallaban especificados los errores más importantes. La segunda (esgrimida básicamente por el Dr. Domingo García), que los argumentos que los lulistas utilizaban para defender a Llull eran del todo desproporcionados, ${ }^{102}$ porque decir, por ejemplo que Llull tenía muchos enemigos porque éstos no habían entendido sus obras, ${ }^{103}$ o sostener que la doctrina de Llull era más sublime que la de cualquier otro autor ${ }^{104}$ eran doctrinas ofensivas y escandalosas.

El maestro Delgadillo aceptó el mandato del Rector y del claustro de no leer el Arte de Ramon Llull, aunque la Suprema no se atrevió a condenar formalmente la lectura del Doctor Iluminado. En esas mismas fechas, como se ha visto antes, el proceso de beatificación de Llull estaba a punto de arrancar en Mallorca y generaba para la Inquisición, en tanto que institución para toda la Monarquía, un conflicto que se fue mitigando con ambigüedad. No hay constancia de que se volviese a leer a Llull en Zaragoza mientras estuvo allí el ilustre carmelita, antes de su marcha a Granada, donde publicó algunas de sus obras más celebradas.

Cabe recalcar que Sánchez de Lizárazu, el legado de Felipe III en Roma para defender los asuntos lulianos a quien antes se ha aludido, fue autor de una vindicación de la obra luliana y de una obra metodológica ${ }^{105}$ basada sobre el Arte de Llull en la línea del enciclopedismo europeo, publicada en Tarazona en 1613, en pleno debate sobre la obra de Llull. Hay que observar, por una parte, que el Maestro Delgadillo pudo conocer los debates lulianos cuando estuvo en Roma en 1609 y, por otra, la cercanía del lugar de publicación de la obra de Sánchez de Lizárazu respecto de Zaragoza. Esto muestra que, ciertamente, el lulismo era en aquel momento un asunto muy espinoso y complejo.

${ }^{102}$ Pinto Crespo. V. 1982: 313.

${ }^{103}$ AHN, Consejo de la Inquisición, L. 970, f. 434 (antigua numeración, f. 426), "quod plurimos habeat adversarios qui omnes illam nec a limine salutarunt nec intellexerunt".

${ }^{104}$ AHN, Consejo de la Inquisición, L. 970, f. 434 (antigua numeración, f. 426).

105 Sánchez de Lizárazu, P. J. 1613. Generalis et admirabilis methodus, ad omnes scientias facilius et citius addiscendas, in qua explicatur Ars brevis Raymundi Lulli..., Tyrasonæ: Per Carolum a Lauayen. 
Sin embargo, el maestro Delgadillo no sólo tuvo problemas en Zaragoza en 1610, sino que al final de su vida fue perseguido también por la Inquisición por su particular aplicación del ars praedicandi de Ramon Llull. ${ }^{106}$ Ciertamente, cuando el carmelita estaba en el punto cimero de su celebridad y fama, después de publicar la Breve y fácil declaración del artificio luliano, fue procesado de nuevo por la Inquisición por la publicación de su Puerta de la $L u z,{ }^{107}$ una obra donde se aplica el arte de la memoria a cuestiones de piedad y religión.

La calificación inquisitorial, ${ }^{108}$ en la que no se entrará aquí en profundidad, ${ }^{109}$ denunció que la mnemotecnia que Núñez Delgadillo aplicaba en esa obra tenía cierto olor a judaísmo. En diferentes lugares se ha repetido la censura que el calificador Juan de Pineda hizo de un argumento sacado del libro: "Si comes una perdiz, mira sus letras y hallarás en la $\mathrm{P}$ la prisión, en la $\mathrm{E}$ el escarnio de la pasión, en la $\mathrm{R}$ el rigor con el que lo trataron, en la De el desamparo que padeció, en la C la cruz..." 110

Sin duda, estas ideas no son lulianas, aunque sí tienen un sabor inconfundible de la aplicación mnemotécnica que se hizo en aquella época del arte de la memoria, ${ }^{111}$ muy afín al interés luliano que había a la sazón en Francia, y que podía resultar temible a los Inquisidores. En España, esta corriente lógico-mnemotécnica se prolongó, aunque de forma degenerada, hasta el siglo XVIII, con figuras como Francisco José de Artiga. ${ }^{112}$ Estas doctrinas resultaron sospechosas a la Inquisición, la cual, durante la segunda mitad del XVII examinó en varias ocasiones proposiciones y escritos lulianos.

106 Véase la tradición del Ars abbreviata praedicandi en el Estudio Preliminar de Raimundi Lulli Opera Latina (ROL) XVIII. 1991: 31-37. Turnhout: Brepols.

107 Núñez Delgadillo, A. 1630. Puerta de la Luz, para conocer y tener presentes en todas las acciones, palabras y pensamientos a Dios nuestro Señor, a Jesucristo, nuestro salvador, su sagrada pasión... á la Virgen soberana y grauedad del pecado por las letras del Abecedario. Zaragoza: Pedro Vergés.

108 AHN, Consejo de la Inquisición, leg. 4444, exp. 45.

109 Véase Ramis Barceló, R. y Serra Zamora, A. 2014: "La censura inquisitorial a Puerta de la Luz de Fr. Agustín Núñez Delgadillo". Revista de la Inquisición 18: en prensa.

${ }^{110}$ AHN, leg. 4444, exp. 45, f. 2 r.

111 Sobre este tema, R. de la Flor. F. 1996. Teatro de la memoria. Siete ensayos sobre mnemotecnia española de los siglos XVII y XVIII. Salamanca: Junta de Castilla y León.

${ }^{112}$ Ramis Barceló, R. 2012: 86-87. 
En otros trabajos he tenido ocasión de examinar esta persecución inquisitorial, especialmente en una censura de libros en México ${ }^{113}$ y un proceso contra el profesor lulista Sebastián Riera, catedrático del Estudio General de Mallorca. En estos casos, como en el que aquí se examina, referente a la Inquisición de Zaragoza, la Suprema tampoco llegó a dar una solución definitiva. ${ }^{114}$ No hubo una condena en firme de la Inquisición durante el siglo XVII, aunque los dominicos y los antilulianos la buscaron denodadamente.

\section{CONCLUSIONES}

La prohibición de la lectura de Llull en Zaragoza a finales de 1610 resultó un punto de inflexión en la historia de las relaciones entre el lulismo y la Inquisición. A lo largo de las páginas anteriores se ha intentado mostrar cómo la tensa relación entre los monarcas de la Corona de Aragón y la Inquisición medieval tuvo su correlato en las fricciones entre la Inquisición Española y los monarcas hispanos, desde los Reyes Católicos hasta los Austrias Menores.

En efecto, los mismos enfrentamientos e incomprensiones ciegas manifestadas en el siglo XIV se repitieron, aunque en un contexto muy diferente, a caballo entre el XVI y el XVII. Ésta es la principal conclusión que se extrae de lo anterior. Debe añadírsele otra: el lulismo fue una ideología o corriente de pensamiento que tuvo mayor o menor clandestinidad durante la época Moderna, pero es indudable su importancia en la historia de las ideas, de las Universidades y de la Iglesia española.

La situación durante el reinado de Felipe II fue muy tensa, pues el Rey quería que Llull fuera canonizado y difundió el lulismo, mientras que los dominicos, recuperando una y otra vez a Eimeric, intentaron introducir a Llull en los Índices tridentinos y posteriores. Mientras la causa luliana empezaba a trabajar, en Roma se procesó y quemó por hereje a uno de los más grandes seguidores de Llull: Giordano Bruno. Las situaciones contradictorias no dejaron de sucederse: frente a las condenas del lulismo en diferentes puntos del territorio hispánico, en Mallorca se iniciaba, por instancias de los Jurados de la Ciudad y Reino, el proceso diocesano de beatificación.

${ }^{113}$ Ramis Barceló, R. 2013b: "La Inquisición de México y la calificación del 'Árbol de Ciencia' de Ramon Llull (1665-1669)". Revista de Estudios Novohispanos, 48: 189-214.

${ }^{114}$ Ramis Barceló, R. 2013c: "El proceso inquisitorial al catedrático lulista Sebastián Riera (1662-1665)”. Revista de la Inquisición, 17 (2013), pp. 117142. 
Hasta 1610 se sucedieron varias derrotas del lulismo académico (principalmente, en Alcalá y Barcelona), pero la del maestro Núñez Delgadillo fue tal vez la más contundente, aunque el carmelita no dejó de profesar el lulismo durante el resto de su vida. La concepción intelectual del maestro Delgadillo fue un apéndice del lulismo peninsular del XVI, pero su temática era objeto de apasionada discusión en la Francia del momento. La paradójica situación mostraba que, al tiempo que se prohibía la explicación pública de Llull, no se podía condenar formalmente su obra por la protección que los Reyes le habían dispensado hasta entonces.

El Doctor lluminado era leído con gran interés y las referencias sobre su obra se pueden encontrar en numerosos impresos y manuscritos del XVII. Sin embargo, la docencia luliana quedó reducida al Estudio General Luliano de Mallorca y a la Orden Franciscana, quienes buscaron testimonios favorables para la canonización de Llull. El ambiente universitario volvía a mostrar una gran paradoja: el Arte de Llull resultaba del máximo interés para los estudiantes, mientras que las autoridades universitarias lo prohibían. Una muestra más del "cordón sanitario", que acabó ahogando incluso a las doctrinas más apreciadas por los Reyes Católicos y por Felipe II. Cabe recalcar, de nuevo, que era una prohibición sin condena expresa, porque entre la bula de Gregorio XI y la Sentencia Definitiva de 1419, la Suprema no sabía cómo proceder sin molestar al Papa ni al Rey. Los argumentos de los compañeros de cátedra de Núñez Delgadillo repitieron una y otra vez el Directorium de Eimeric y consiguieron que no se leyera a Llull en sede Universitaria, pero no pudieron prohibir la circulación de sus ideas.

A partir de 1610 el lulismo peninsular empezó, sin duda, una fase de mayor clandestinidad. Las obras lulianas que se publicaron en la Península a partir de entonces fueron muy tangenciales. Núñez Delgadillo siguió creyendo y valorando la doctrina luliana hasta su muerte, acaecida en 1631, y ello le reportó numerosos problemas con la Inquisición. Siguiendo la línea alcalaína de Pedro de Guevara, el carmelita mostró a lo largo de su vida su interés por Llull en una época en la que la Inquisición había limitado mucho el alcance de las doctrinas del Doctor lluminado. Sólo aquellos lulistas españoles de generaciones posteriores, como Alonso de Cepeda o Sebastián Izquierdo, que estuvieron largos períodos fuera de la Península, pudieron realizar una cierta "integración europea" del lulismo hispano. Queda por estudiar con mayor detalle el lulismo alcalaíno del XVI y del XVII: el apéndice documental da pistas de interés al respecto.

Cada uno de los documentos inéditos que se van conociendo corrobora la idea de que Llull era un autor muy leído y presente en las aulas y conventos de la Península. Sin duda, la Petición del Fiscal del 
Santo Oficio de Zaragoza a la Suprema revela el desconcierto sobre qué tenían que hacer con Ramon Llull, puesto que no había una solución clara acerca de su doctrina. Todos los procesos inquisitoriales de la España del XVII acababan en un sobreseimiento por parte de la Suprema, que no sabía cómo atacar el problema.

En fin, el lulismo peninsular exigiría un estudio similar al que Bataillon dedicó a Erasmo, ${ }^{115}$ pues cada vez que se conoce con mayor precisión el mapa de los saberes y los intereses durante la época de los Austrias, se tiene que admitir con más claridad el peso que jugó el lulismo. Fue una doctrina tan importante como ambivalente, tanto en sede universitaria como fuera de ella, tal y como sugirió Melquíades Andrés en su célebre trabajo de síntesis sobre la teología española del $\mathrm{XVI} .{ }^{116}$ Las páginas anteriores y el apéndice de nuevos documentos no hacen sino intentar contribuir a un mayor conocimiento del lulismo hispano que, por las difíciles circunstancias en las que se desarrolló y por lo fragmentario y sutil de su manifestación, sigue suponiendo un reto para los investigadores.

\section{APÉNDICE DOCUMENTAL ${ }^{117}$}

\section{DOCUMENTO I}

AHN, Consejo de la Inquisición, L. 970, ff. 443-444 (antigua numeración, ff. 435-436)

Raymundo Lullio fue en el tiempo de alexandro quarto en el año 1260 como refiere Protocolo lib. 16 de vistis et sectis hereticorum cap. 2 bernardus luxemburgus in catalogo heretico libro 3 eymericus 2 pars Directorium Inquisitorum in quaestionem nonam el qual fue de Mallorca ignorante pues no supo perfectamente gramatica cuya doctrina aun el dice la recibio del Espiritu Santo en el monte de Mallorca que agora se dice Randa el cual se aparecio crucificado con todo ese es muy probable que la recibio del demonio la qual duro ochenta años hasta que Eymerico frayle dominico inquisidor de Aragon tomandola por sospechosa en la fe la embio al Papa Gregorio Undecimo que eran veynte cuerpos el qual remitialos al cardenal hostiense con parezer de veynte theologos comandaron prohibir por tener quinientos errores en ella y de los ciento principales hace mencion Eymerico para describir en que esta prohibición consta por la bulla de Gregorio undezimo en las extravagantes que

115 Bataillon, M. 1966. Erasmo y España: 54-55. México: FCE.

116 Andrés, M. 1976: 294.

117 Para facilitar la lectura del apéndice documental, transcrito siguiendo el tenor literal de los manuscritos, se han puesto los textos en latín en letra cursiva. 
embio al arçobispo de Tarragona que comiença Gregorio en la qual dice ceteram quia doctrina seu potius dogmaticalia predi[c]torum librorum craminatorum reperatur erronea hereticalis et pericula nimium animabus et vehemens suspitio est habenda quod in allis libris a dicto raymundo similes vel alii sicut prefertur, contieniant errores, nobis mandamus in doctrinam sic potius dogmaticationem et usum huiusmodo librarum interdicere estudentes, donec supra his per sedem apostolicam allud fuerat ordinatum y esto mismo sintio este papa antes que la condenase esta doctrina como epistola que enbio al arçobispo de Tarragona que comiença nuper dilecto fillio como consta en vaticana biblioteca in volumine registrum 2 follio 131 qua percepit docto archiepiscopo ut sibi faciat exibiri libros raymundi luli in quibus quam pluram errores dicebantur contineri, et in volumine scado. regesti anni quarti foll. 201 extant littera eiusdem Gregorii et conversam ad adientiam, quibus praecipuntur oficialibus episcopi barcinonensi ut transmitant ad dominum papam librum quidam Raymudi Lullii est in quo similiter plurimum errores scripsi continetur.

Y ni solo ha sentido el Pontifice Gregorio esto de la doctrina de Lullio, pero los que han sido su[sten]tadores de la doctrina de la misma vemos que ha habido por defenderla doce errores notables por entender que nuestra manera de dificultad la puedan definir como es que Jesucristo se le aparecio crucificado y se le dio a Lullio aquella doctrina, que excede aquesta doctrina a las demas en verdad y en bondad aunque sea esta que si no S. Agustin que los theologos durante tiempo no saben lo que es acertado en teologia, y que por los pecados de los que agora son los theologos se les ha quitado y concedido a los lulistas, que todas las doctrinas se han de acabar sino esta, que en el tiempo del anterior todos los que somos theologos havemos de apostatar y que entonces los lullistas recobraran a la fe de la Yglesia catolica y la doctrina de Raimundo Lullio se le atribuye al Espiritu Santo y esa no se puede alcançar, sino por revelaçion, que esta por revelaçion del Espiritu Santo se alcanza en treinta quarenta cinquenta o sesenta horas, que esta no la pueden alcanzar sino los lulistas, que erro el papa y los que le asistieron al condenar aquellos quinientos errores que se hallaron en sus libros, que Lullio es bien aventurado.

Y siendo esto ansi y que el autor de esta doctrina tuvo tal reputacion acerca del Papa Gregorio y los errores que han tenido sus su[sten]tadores son tan grandes como por aquí consta me parece que aunque en este libro se abla de arte parva et magna no sea de los 20 que condeno el papa Gregorio undecimo en avinon en consistorio estado comisariado el cardenal hostiense para la ciencia que en el se ensena es vana inutil por nada mas que ser tan diferente y distante a la doctrina de los Santos y Doctores de la Iglesia Romana en la qual se ha aprovechado la Theologia Sagrada, de asiomas, concillios, explicaciones 
de articulos de fe interpretacion de la Sagrada Scriptura, hacer nuebos canones y leyes, conservar la perfeccion cristiana: es doctrina Peregrina y la mas osada de las que han regido y definido la religion cristiana y doctrina muy ocasionada para introducirse con ella nuevos errores si en la theologia obserba la Santa Madre Yglesia como en la tradicion de la sagrada escriptura, ora por no poder se penetrar de todos sus fundamentos, ora por no ser en si estables ni firmes ni suficientes de ninguna manera para con ellos poderse conseguir lo que proponen y declara solo de impedir la leccion de los santos y doctores escolásticos con que se ha defendido mediante la revelacion del Espiritu Santo de tantos errores nuestra Sagrada Religion como se han llebantado contra ella y asi sea bien que como poste tan nociva hen comun de la religion se impida con grandes veras, com se colige de S. Pablo Tim. 13 doctrinis variis et peregrinis nollite abduci, ipsis 4 utram non sumus parbuli et circumferamur omnibus doctrine ut iam ad timote stultas et sine disciplina questiones devita et ad totum profanas vocum novitates devita.

Y esto mismo nos enseñan el ver que despues se invento esta scientia que ha mas de 340 años en los concilios generales ni aun provinciales no sean aprovechado jamás della y con haver gloriado sin duda algunas personas muy eminentes a su parecer en ella no han sido bastantes para persuadir a los concillios para que se instituyesen cathedras della en las universidades como se han hecho para la lengua hebrea caldea y arabiga por ser importantes al bando de nuestra santa religion et in clementi 1 titulo ubi.

$Y$ esto mismo confirma el no haver permitido en las universidades insignes de España como es Alcala Salamanca Valladolid se leyese en ella esta sciencia y quando se intento en Alcala abra 24 años por provision real a instantia del Doctor Dimas gran lulista viendo que con sus principios le probaban hasta nueve personas divinas no permitieron se leyese mas de un mes y esto fue con parecer de las personas mas graves della y habiendo tomado aquella resolución sin hacer agravio a nadie es madre de la buena y catolica theologia escholastica como theologia y conocen lo de las demas universidades aceptada cosa sera y esta se confirma con ella a mas que haciendo esto vayan tan al seguro en todo me remito al [informe que dare] oy lunes.

El Dr. D. Garcia

DOCUMENTO II

AHN, Consejo de la Inquisición, L. 970, ff. 439-440 (antigua numeración, ff. 431-432). 
El promotor fiscal de la fee en este oficio digo que en noticia a llegado, que el maestro delgadillo del convento del Carmen a publicado, y leido en la universidad de esta ciudad una lectura del arte parva et magna de Raimundo Lull, a la cual consferancias; que ande salir en breve tiempo mas doctos que con ninguna otra doctrina, concurren a esta liçion mas oyentes, que a ninguna otra de las que se leen de autores recibidos y grabes; y de que se permitta dicha lectura se representan muchos incombenientes, y entre otros, que siendo este autor condenado por hereje y condenado demás de quinientos herrores es grandissimo que resucite su doctrina y que publicamente se lea en universidades donde a vuelta de la universidad, y brevedad de la doctrina podría beber la juventud la heregia i errores de que dicho autor esta notado, y entre estas cosas que en las leciones, que dicho maestro delgadillo asta ahora dize las palabras siguientes: de autore vero nobis nunc dicam spero enim prope diem illius vitam tipis mandandam atque seniam a iudice apostolico in illis favorem prelatam (quae ad meas iam pervenit manus simul etiam in lucem adendam) y dice ansimismo mas adelante: de arte vero suis autoribus nec ullus unque fuit errores escrupulosus, immo nec esse potest, y da la raçon perque tota ars fundata est in literis alphabeti; y estando dicho autor condenado por hereje, y convencido de tantos errores como esta dichos son terribles proposiciones las dichas ademas que dice otras aeste modo como constara en la lectura, y pues en las universidades de Salamanca, Alcala y las demás aprobadas no sea leído este autor, es de mucho peligro el començar a introducir su doctrina en esta universidad donde tenemos por vecinos a muchos herejes de françia, y de otras partes infectas, y esta ciudad llena de françeses i podria inficionarse la juventud con alguna mala doctrina, y esparcerse de suerte, que no fuese facil el remedio de ella, y pues en tiempo del rei nuestro señor Philipe segundo pretendieron los Mallorquines, que en todas las universidades de la corona se instituyese cathedra de esta facultad y que ellos pagarían a su costa los estipendios a los maestros y su magestad con gran prudencia y zelo no lo permittio; bien cierto es no convenia y ansimesmo a llegado a mi noticia que abiendo demandado a dicho maestro Delgadillo por el rector, y claustro de esta Unibersidad prosiguiese en dicha lectura por ser de la calidad dicha no solamente no lo a echo, mas antes con animo de proseguir y acabar de leer la a publicado de nuevo en la universidad para la yr leyendo, y prosiguiendo en el convento de su orden en esta ciudad.

Por todo lo cual pido y suplico a vuestra señoria se reciba información de todo lo susodicho la qual desde lo que ofresco, para que en cuenta de ella pida contra el susodicho lo que viere conviene a mi derecho y para ello etcetera.

Otrosi digo que siendo relator del consejo de su magestad de la santa general inquisicion me quiero dar su relaçion de cierta testificación 
que la inquisicion de Sevilla se remitio contra dicho maestro delgadillo, pido, y suplico a vuestra señoria se de quenta a los señores del consejo para que ordenen a los inquisidores de Sevilla remittan dicha testificaçion aeste tribunal, para que se junte con los demas papeles contra dicho reo. El qual ademas de lo dicho pareçe ser persona sospechosa por aber oydo que no solo no es Limpio, mas ante descendiente de judios.

Y entodo pido cumplimiento de la justicia. Etcetera.

Llicenciado Pedro Fernandez de Çea

\section{BIBLIOGRAFÍA}

Alegre de Casanate, M. A. 1639. Paradisus Carmelitici decoris. Lugduni: lacobi \& Petri Prost.

Alvar. E. 1980. "Exequias y certamen poético por Margarita de Austria (Zaragoza, 1612)", Archivo de filología aragonesa, 26-27: 355389.

Andrés, M. 1976. La teología española en el siglo XVI, Vol. I. Madrid: BAC.

Antonio, N. 1783. Bibliotheca hispana, vol. 1. Madrid: Joaquín de Ibarra.

Barea López, O. 2012. Heráldica y genealogía de Cabra de Córdoba, Doña Mencía y Monturque y de sus enlaces (ss. XV-XIX), II. Bubok Publishing.

Bataillon, M. 1966. Erasmo y España. México: FCE.

Beltrán de Heredia, V. 1973. "La teología en nuestras universidades del Siglo de Oro", en Miscelanea Beltrán de Heredia, t. IV: 447-448. Salamanca: San Esteban.

Camón y Tramullas, I. 1768. Memorias literarias de Zaragoza. Zaragoza: F. Moreno.

Carreras Artau, J. y T. 1941. Historia de la filosofía española. Madrid: Real Academia de Ciencias Físicas.

Contreras, J. 1982. El Santo Oficio de la Inquisición de Galicia. Madrid: Akal. 
DE RAMON LLULL EN LA UNIVERSIDAD DE ZARAGOZA (1610)

Díaz Díaz, G., 1995. Hombres y documentos de la filosofía española, vol. 5. Madrid: CSIC.

Fernández Luzón, A. 2005. La Universidad de Barcelona en el siglo XVI. Barcelona: Edicions de la Universitat de Barcelona.

Fuertes Herreros, J. L. 1981. La lógica como fundamentación del arte general del saber en Sebastián Izquierdo: estudio del "Pharus scientiarum" (1659). Salamanca: Universidad de Salamanca.

Garrido, P. M., 1982. Santa Teresa, San Juan de la Cruz y los carmelitas españoles. Salamanca: Universidad Pontificia de Salamanca.

Guevara, P. 1584. Arte general y breve, en dos instrumentos, para todas las ciencias. Recopilada del Arte magna y del Arbor scientiæ del doctor Raymundo Lulio. Madrid: herederos de Alonso Gómez.

Izquierdo, S., 1659. Pharus scientiarum. Lugduni: C. Bourgeat [et] M. Lietard.

Jiménez Catalán, M. y Sinués y Urbiola, J. 1924. Historia de la Real y Pontificia Universidad de Zaragoza. Zaragoza: Tipografía La Académica.

Martínez Carretero, I. 2009. Los Carmelitas en Sevilla. 650 años de presencia (1358-2008). Sevilla: Provincia Bética de PP. Carmelitas.

Mercanti, A. 1961. Il sommario del proceso di Giordano Bruno. Città del Vaticano: Biblioteca Apostolica Vaticana.

Muzzi, S. (ed.) 2010. Da Raimondo Lullo a Nicola Eimeric. Storia di una falsificazione testuale e dottrinale. Roma: Antonianum.

Núñez Delgadillo, A. 1617. Sermon de la gloriosa Sancta Teresa de lesvs, predicado en el Conuento de las Carmelitas Descalças de Granada, Lunes de su octaua. Por el Padre Maestro Fray Augustin Nuñez Delgadillo, Carmelita Lector de prima de Theologia, y Regente de los estudios en el Conuento de Nra. Señora de la Cabeça de la mesma Ciudad. Granada: Imprenta de Juan Muñoz.

Núñez Delgadillo, A. 1627. Artificio breve y muy claro para discurrir sin mucho estudio, y con superioridad en toda materia de costumbres. Cuenca: Domingo de la Iglesia. 
Núñez Delgadillo, A. 1629. Minas celestiales descvbiertas en los evangelios de qvaresma destribvidas en sermones. por el padre maestro fray Agustin Nuñez Delgadillo de la Orden de nuestra Señora del Carmen de la Obseruancia, antes Catedrático propietario de Teologia Escolástica en la Universidad de Zaragoca, y aora Predicador del convento de nuestra del Carmen de Madrid, Corte de su Magestad, Madrid: Viuda de Luis Sánchez.

Núñez Delgadillo, A. 1630. Puerta de la Luz, para conocer y tener presentes en todas las acciones, palabras y pensamientos a Dios nuestro Señor, a Jesucristo, nuestro salvador, su sagrada pasión... á la Virgen soberana y grauedad del pecado por las letras del Abecedario. Zaragoza: Pedro Vergés.

Núñez Delgadillo. 1624. Breve y fácil declaración del artificio Iuliano, provechosa para todas las facultades. Alcalá: Juan Gracián.

Perarnau Espelt, J. 1997. De Ramon Llull a Nicolau Eimeric. Barcelona-Ciutat de Mallorca: Facultat de Teologia de Barcelona, Centre d'Estudis Teològics de Mallorca.

Pérez Martínez, L. 1960. "El maestro Daguí y el lulismo mallorquín de fines del siglo XV, Estudios Lulianos, 4: 291-306.

Pérez Martínez, L. 1961. Intervención de la Santa Sede en la Causa Luliana Roma: Universidad Gregoriana [Tesis doctoral inédita].

Pérez Martínez, L. 1962. "La causa luliana en Roma durante el reinado de Felipe II", Anthologica Annua 10: 193-249.

Pérez Martínez, L. 1970. Los jurados de Mallorca y la Institución de la Causa Pía Luliana. Palma: Ajuntament de Palma.

Pérez Martínez, L. 1989. "Lulismo e Inquisición a principios del siglo XVII": 727-751. Escudero, J. A. (ed.): Perfiles jurídicos de la Inquisición española. Madrid: Universidad Complutense de Madrid.

Pinto Crespo, V. 1982. "La censura inquisitorial, inquietud e incertidumbre: el caso de Ramon Llull (1559-1610)", Miscelánea de la Universidad Autónoma de Madrid: 293-314. Cantoblanco: Universidad Autónoma de Madrid.

Polo Carrasco, J. 1984. "Los juramentos inmaculistas de la Universidad, Cabildo Catedralicio y Ciudad de Zaragoza (1617-1619)", Cuadernos de historia Jerónimo Zurita, 49-50 (1984): 87-117. 
DE RAMON LLULL EN LA UNIVERSIDAD DE ZARAGOZA (1610)

Puig, J. de. 2000a. "El "Dialogus contra lullistas", de Nicolau Eimeric, O.P. Edició i estudi", Arxiu de textos catalans antics, 19: 7-296.

Puig, J. de. 2000b. "La sentència definitiva de 1419 sobre l'ortodòxia lul.liana. Contextos, protagonistes, problemes", Arxiu de Textos Catalans Antics 19: 297-388.

R. de la Flor. F. 1996. Teatro de la memoria. Siete ensayos sobre mnemotecnia española de los siglos XVII y XVIII. Salamanca: Junta de Castilla y León.

Raimundi Lulli Opera Latina (ROL) XVIII. 1991. Turnhout: Brepols.

Ramis Barceló, R. 2010. "El lul-lisme i l'antilul-lisme dels juristes mallorquins als segles XVII i XVIII" Studia Lulliana 50: 73-95.

Ramis Barceló, R. 2012. "Un esbozo cartográfico del lulismo universitario y escolar en los Reinos Hispánicos", Cuadernos del Instituto Antonio de Nebrija de Estudios sobre la Universidad, 15/1: 61-103.

Ramis Barceló, R. 2013a. "En torno al escoto-lulismo de Pere Daguí", Medievalia 16: 235-264.

Ramis Barceló, R. 2013b. "La Inquisición de México y la calificación del 'Árbol de Ciencia' de Ramon Llull (1665-1669)". Revista de Estudios Novohispanos, 48: 189-214.

Ramis Barceló, R. 2013c. "El proceso inquisitorial al catedrático lulista Sebastián Riera (1662-1665)". Revista de la Inquisición, 17 (2013), pp. 117-142.

Ramis Barceló, R. y Serra Zamora, A. 2014. "La censura inquisitorial a Puerta de la Luz de Fr. Agustín Núñez Delgadillo", (en prensa).

Rodríguez Carretero, M. 2000. Epitome historial de los Carmelitas de Andalucía y del Reino de Granada. Sevilla: Grafisur.

Rodríguez Marín, F. 1889. Apuntes y documentos para la historia de Osuna. Osuna: Imprenta de M. Ledesma Vidal.

Sánchez de Lizárazu, P. J. 1613. Generalis et admirabilis methodus, ad omnes scientias facilius et citius addiscendas, in qua explicatur Ars brevis Raymundi Lulli... Tyrasonæ: Per Carolum a Lauayen. 
Santamaría, A. 1983. La promoción universitaria en Mallorca. Palma: Annex.

Sarrión, A. 2006. Médicos e Inquisición en el Siglo XVII. Cuenca: Universidad de Castilla-La Mancha.

Serrera Contreras, R. M. y Sánchez Mantero, R., 2005. La Universidad de Sevilla, 1505-2005. Sevilla: Universidad de Sevilla.

Trias Mercant, S. 1985. Història del pensament a Mallorca. I, Palma: Moll.

Trias Mercant, S. 2009. Diccionari d'escriptors lul-listes. UIB-UB, Palma-Barcelona.

Vázquez, G. 1598. Opera Theologica Omnia. Compluti: Ex officina loannis Gratiani.

Velasco Bayón, B. 1954. Historia del Carmelo español: Provincias de Cataluña y Aragón y Valencia, 1563-1835. Roma: Institutum Carmelitanum.

Vargas, M. de. 1658. Tesoro de la memoria y del entendimiento y arte facil y breue para toda sabiduría, Madrid: Imprenta Real.

Wilkinson-Zerner, C. 1993. Juan de Herrera, Architect to Philip II of Spain. New Haven/Londres: Yale University Press. 